\title{
Malignancy in scars, chronic ulcers, and sinuses
}

\author{
A. H. CRUICKSHANK, E. MAVIS MCCONNELL, AND D. G. MILlER \\ From the Department of Pathology, University of Liverpool, the Liverpool Radium \\ Institute, and the Warrington Infirmary, Warrington, Lancashire
}

SYNOPSIS A collection of 44 cases of malignancy in scars, chronic ulcers, and sinuses, included the following predisposing lesions: a 20-year-old sinus from ischial bursitis, a 23-year-old bed sore, a congenital gumma about 50 years old, three burn scars (average age of scar 56 years), 11 sinuses from chronic osteomyelitis, and 27 chronic ulcers of the leg. The osteomyelitis cases included two rapidly fatal sarcomas, one in a sinus present for 16 years, the other in a 20 -year-old sinus. The remaining tumours in this group were squamous carcinomas that developed in sinuses with an average duration of 37 years. In the cases of varicose ulcer, the ulcer had been present on the average for 21 years before the onset of malignancy. One patient in this group, with an ulcer not known to be more than five years old, developed a sarcoma that was fatal in six months. The biopsy diagnosis was difficult in 17 cases, including one of the cases of sarcoma. The difficulty was greatest in cases of osteomyelitis. The conditions discussed are now known as 'Marjolin's ulcer'. In the present series, the degree of malignancy in tumours arising in scars may be low but the malignancy of tumours arising in chronic ulcers and sinuses may be high.

Although chronic ulcers of the leg are common and often last for many years, malignant change in such ulcers, the so-called Marjolin's ulcer, is rarely seen now (Dodd and Cockett, 1956). Malignancy that develops in scars or in chronic sinuses, now rare too, is included in the modern definition of Marjolin's ulcer (British Medical Dictionary, 1961). Because such lesions are rare it seemed worthwhile to undertake a study of 44 cases of malignant change in scars, sinuses, and ulcers recorded in the files of the Liverpool Cancer Control Organization. The clinical notes, slides of the biopsy, and excision or amputation specimens with, in many cases, preserved gross specimens, were reviewed and collated with the progress of the cases. The cases are arranged according to the predisposing lesions in Table I. Cases of malignant change in long-standing lupus vulgaris and cases with the microscopic appearances of basal cell carcinoma were excluded from our series.

\section{UNUSUAL CAUSES}

The more unusual predisposing causes included a case of ischial bursitis in a woman of 47 who had had a sinus of the buttock following incision of a septic ischial bursa 20 years before. During much of the time the sinus appears to have caused little

Received for publication 22 March 1963
TABLE I

ANALYSIS OF CASES ACCORDING TO PREDISPOSING LESION

\begin{tabular}{lc} 
Predisposing Lesion & No. of Cases \\
\hline Sinus from ischial bursitis & 1 \\
Bed sore & 1 \\
Congenital syphilis & 1 \\
Burn scars & 3 \\
Chronic osteomyelitis & 11 \\
Ulcer of leg (Wassermann reaction positive) & 3 \\
'Varicose' ulcer & 24 \\
Total & 44
\end{tabular}

trouble but eventually it made her seek advice. At first tuberculosis was suspected clinically but biopsy showed a keratinized squamous carcinoma. The tumour was excised radically but recurred, metastasized, and caused death in eight months.

The case with the bed sore (Fig. 1) was a man of 49 who had been temporarily paraplegic as a result of Pott's disease 23 years earlier. While paraplegic he had developed bed sores and one, over the left trochanter, had never healed completely. When malignancy was recognized in the ulcer, the limb was disarticulated at the hip but death due to multiple secondary deposits occurred within a few months.

The case of congenital syphilis (Fig. 2) was a woman of 57 who had had a discharging sinus from 


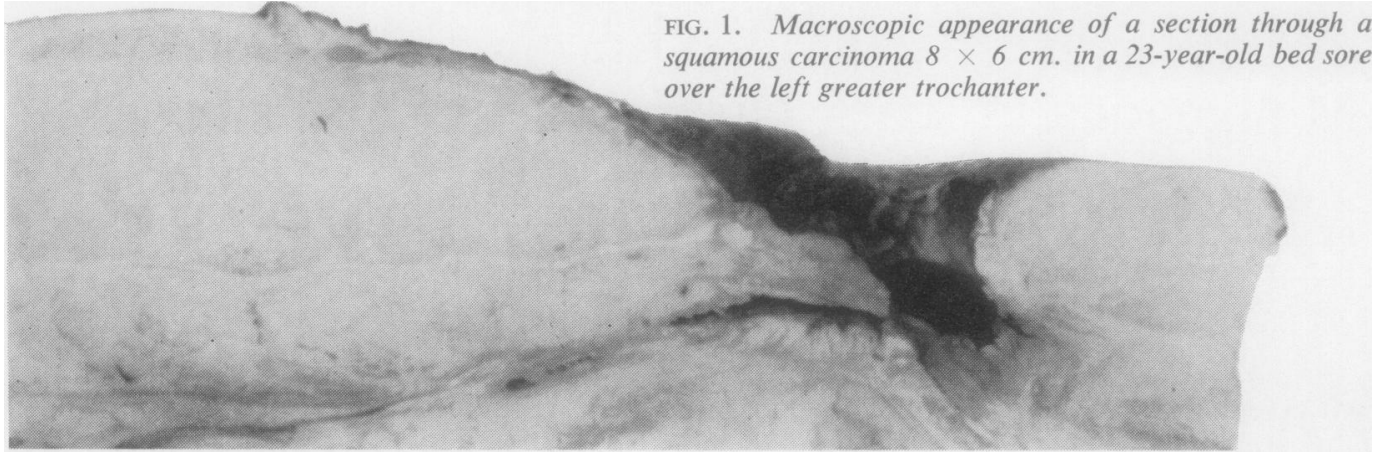

FIG. 2. Sagittal section through a squamous carcinoma in a sinus due to congenital syphilis of the tibia.
The three carcinomas that developed in the scars of burns all had a very long latent period (average $56 \cdot 3$ years). This is shown in Table II. All the cases were in men. All appear to have been cured by local excision, one has had no recurrence for five years, one for four years, and the third has no recurrence after one year. We found no case of malignancy in scars other than burn scars but there have been reports in the past of malignancy in the scars left by floggings (Hawkins, 1835; Smith, 1850).

TABLE II

CARCINOMA IN BURN SCARS

a gumma of the right upper tibia since early childfor many years but, when her father died, examination of his papers gave a hint which led to serological syphilitic. Treatment with penicillin caused improvement but a small sinus persisted and, after 10 years, Biopsy established the diagnosis of squamou carcinoma and amputation was carried out above the knee; the patient was well one year later.

\section{BURN SCARS}

\begin{tabular}{ccc} 
Age of Patient $(y r)$. & Age of Scar $(y r)$. & Site \\
\hline 45 & 44 & Face \\
78 & 77 & Face \\
76 & 48 & Axilla \\
& & \\
& OSTEOMYELITIS &
\end{tabular}

$$
\text { Age of Scar (yr.) }
$$

Of the 11 cases of malignancy in sinuses due to osteomyelitis, the osteomyelitis had been caused by compound fractures in seven cases, by haematogenous infection in one case, while in three the cause $\overrightarrow{0}$ of the osteomyelitis was not recorded. As is usual in $\mathbb{\mathbb { D }}$ osteomyelitis there was a male preponderance $\overrightarrow{\mathbb{D}}$ (eight males to three females). Except for one case 
with a sinus in the groin after a compound fracture of the pubis the sinuses were in the lower leg or foot.

In two of the cases (one male, one female) the tumour was a sarcoma, in the other nine it was a squamous carcinoma.

In the two sarcoma cases the sinuses had been present for 16 and 20 years. Both were treated by amputation but both died of metastases within five months of operation.

In the nine cases of carcinoma the average age of the patient was 57 years and the average duration of the sinus before the diagnosis of malignancy was established was 37 years (range 18 to 46 years). Surgical treatment was impossible for the patient with the sinus in the groin following osteomyelitis in the pubis and he died within six months of the diagnosis of malignancy. One patient was treated by local excision and the other nine by amputation. One of these died a year after amputation and the fate of one patient could not be ascertained. All the others were well at least one year after amputation and four were free from tumour at least five years later.

Despite the fairly high cure rate among the cases of carcinoma, the follow-up indicates that the tumour may have sufficient malignancy to kill even after amputation, and if the tumour takes the form of sarcoma even amputation is unlikely to produce a cure.

\section{CHRONIC ULCERS OF THE LEG}

Of the 27 cases in this group 24 were cases of 'varicose' (venous) ulcers; the other three had ulcers and serological evidence of syphilis.

In two of the latter group the ulcers were indistinguishable from 'varicose' ulcers, in the third the leg was described as wasted and scarred and the ulcer was said to have been much improved by antisyphilitic treatment, although it never disappeared completely. In this small group one of the cases of 'varicose' ulcer (a man) died of metastatic squamous carcinoma despite several local excisions and a final amputation. The other two (one man and one woman) were cured by amputation and have remained well for four and six years respectively since.

Among the 24 'varicose' ulcer cases without syphilis, one, a man of 84 , developed a sarcoma in an ulcer that was not known to have been present for more than five years, although it is suspected to have been present for many years longer. Amputation was refused and the sarcoma killed him in six months. The 23 cases that developed carcinoma were made up of 19 women and four men. In the 20 cases in which the duration of the ulcer was known the average was 21 years (range three to 40 years).
Of 16 patients who were treated by amputation, four died within a year of the amputation, three of metastatic carcinoma and one of unrelated disease; five patients have been followed for less than a year and two have been lost from the follow-up; of the remaining five, one died of unrelated disease four years after the amputation and the other four are cured seven, nine, 10, and 13 years, respectively, after the amputations.

Of six patients treated by local excision, one died of unrelated disease within the first year after the operation, one died of unrelated disease four years after, and the remaining four are alive six, seven, nine, and 10 years, respectively, after the operations.

The one patient who was treated by radium had a recurrence of the tumour 11 years after the treatment had been completed but was still alive at the time of the follow-up.

\section{HISTOLOGICAL STRUCTURE OF THE TUMOURS}

CARCINOMAS These were all keratinized squamous cell carcinomas. No histological difference could be recognized between those that developed in scars, sinuses, or ulcers. In two patients there were, in addition to the areas of undoubted squamous carcinoma, areas of spindle cells that caused a suspicion that the tumours might be carcinosarcomas but both patients were cured by amputation and were well several years later.

SARCOMAS These were myxomatous growths of spindle cells with so many blood vessels that their appearance suggested granulation tissue that had undergone malignant transformation. They contained no prickle cells, keratin, or other evidence that they were anaplastic epithelial tumours. Their highly malignant behaviour was in keeping with the diagnosis of sarcoma.

\section{DIFFICULTIES IN HISTOLOGICAL DIAGNOSIS}

In 16 of the 41 cases of carcinoma there was difficulty or actual error in the biopsy diagnosis. In a few cases the sample was not truly representative, but the main cause of delay in diagnosis was caution in the interpretation of apparently invasive epithelial processes lest the condition should be one of pseudo-epitheliomatous hyperplasia. Even in some cases in which the diagnosis seemed obvious clinically, e.g., that shown in Fig. 3, biopsy was sometimes inconclusive. The condition of pseudoepitheliomatous hyperplasia was recognized by White and Weidman (1927) who pointed out that it is sometimes impossible to distinguish histologically 
FIG. 3. Clinically obvious carcinoma in a chronic ulcer of the leg.

s.



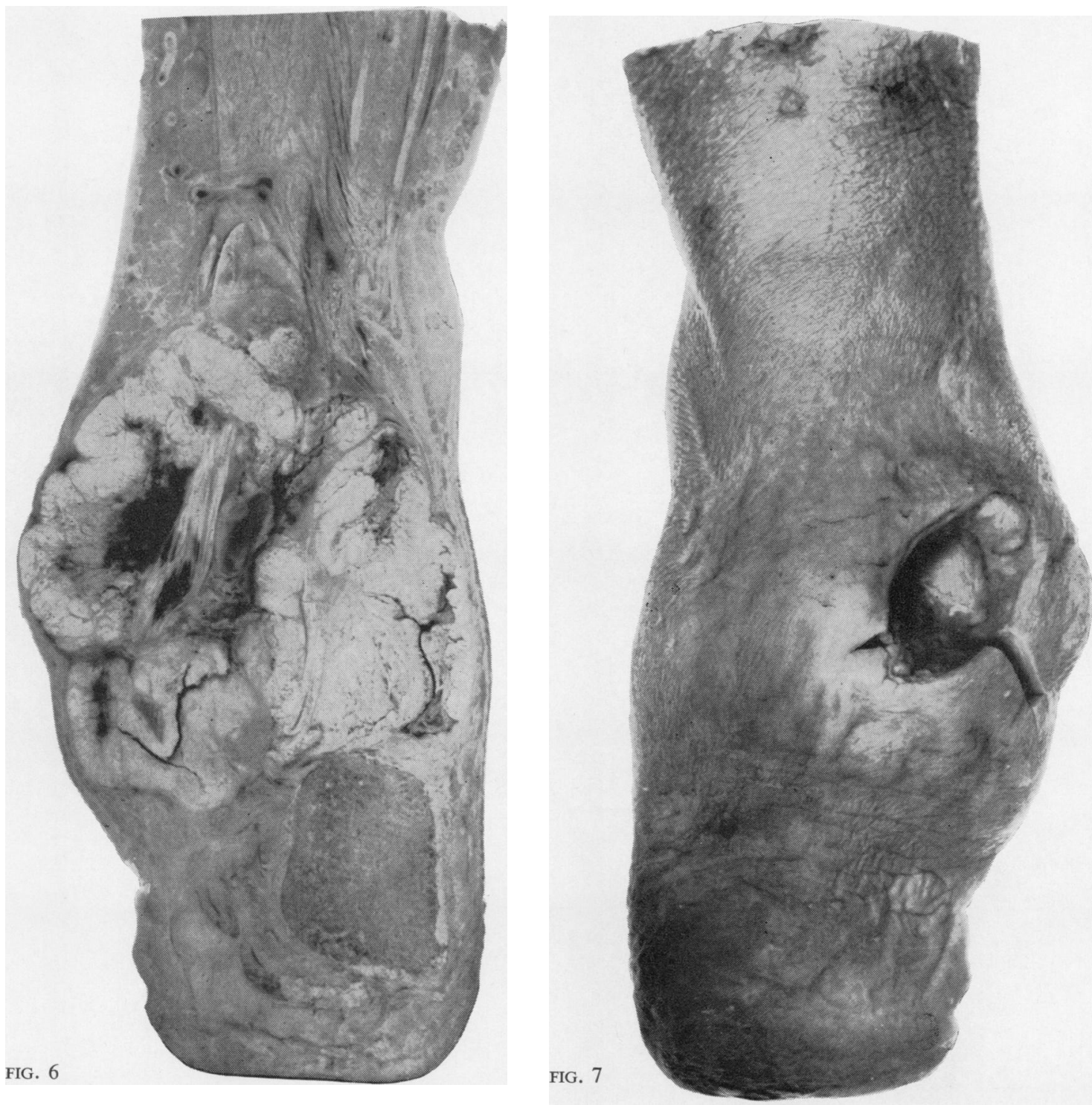

FIG. 6. Cavity of chronic osteomyelitis now filled by squamous carcinoma.

FIG. 7. Orifice of the sinus to the surface in the same case as that illustrated in Figure 6. The scars of healed sinuses are present higher up the leg. 


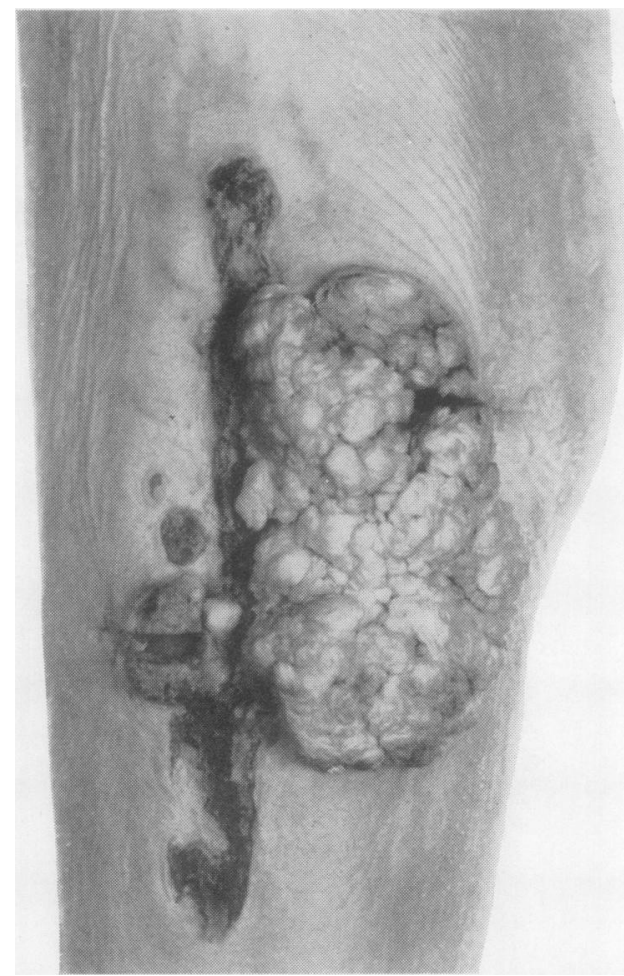

FIG. 8.

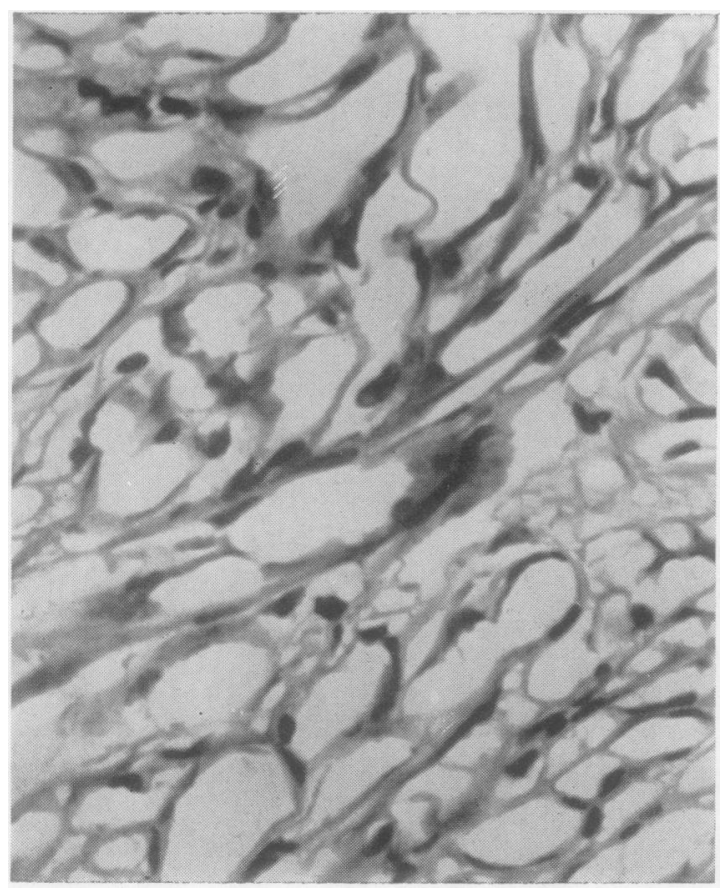

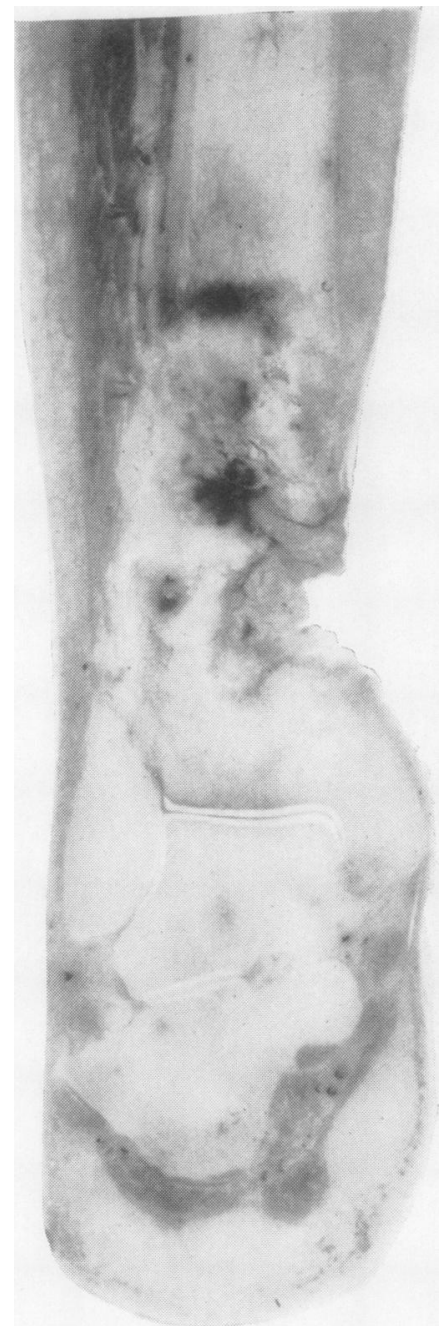

FIG. 9.

FIG. 8. Papillary squamous carcinoma at the margin of a
sinus in chronic osteomyelitis. FIG. 9. Sarcoma in the cavity of chronic osteomyelitis. 온 FIG. 10. Sarcoma that was mistaken for vascular granu-O lation tissue. There is distortion because the specimen hado been frozen before fixation. Haematoxylin and eosin $\times 630$.

FIG. 10 . 


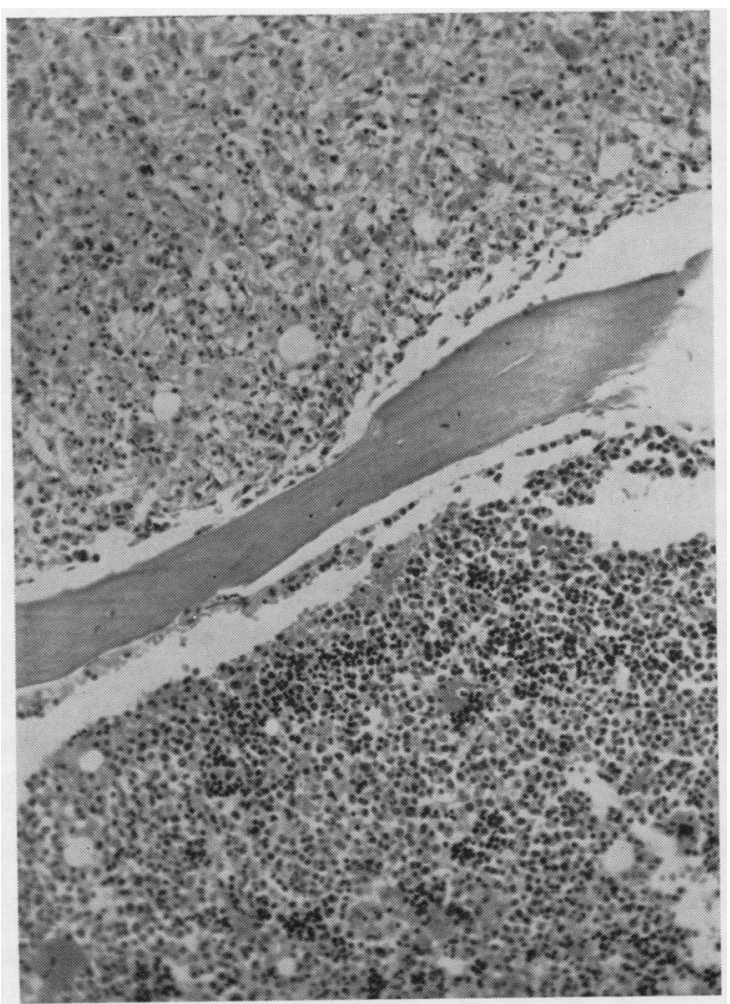

FIG. 11 .

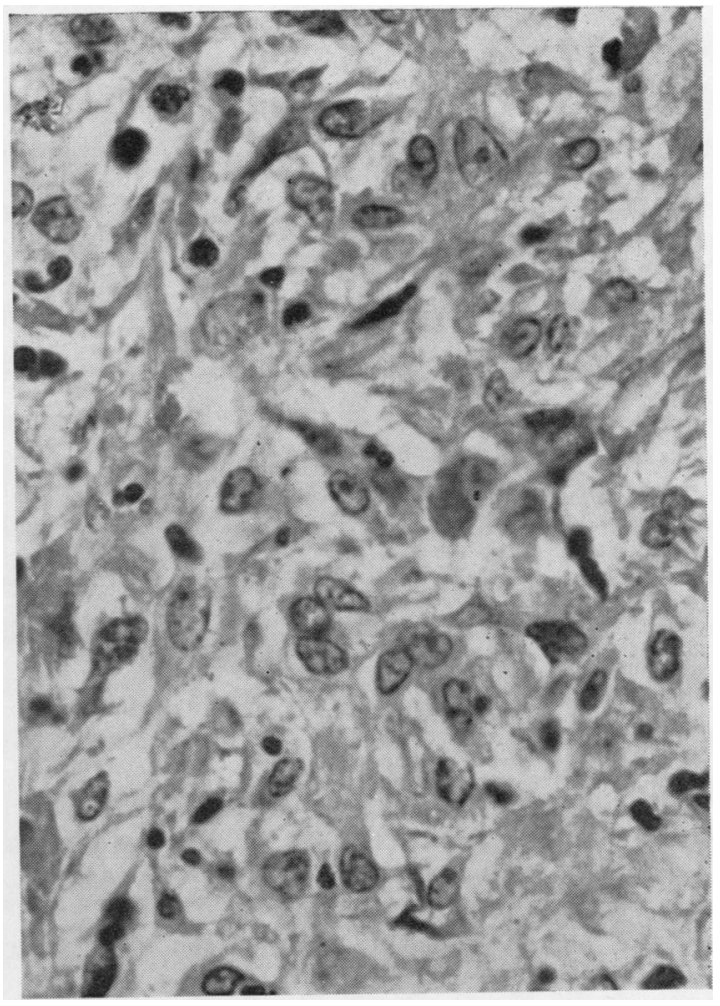

FIG. 12.

FIG. 11. Vertebral body with secondary deposit of sarcoma following chronic osteomyelitis. The upper half of the field is tumour, the lower is normal bone and haemopoietic marrow. Haematoxylin and eosin $\times 130$.

FIG. 12. Higher magnification of the tumour in Figure 11. Haematoxylin and eosin $\times 630$.

between squamous cell cancer and benign hyperplasia. They made a plea for caution in the interpretation of histological signs of early malignancy at the edge of a chronic ulcer, and advised against a confident diagnosis of malignancy unless invasion had reached the level of the sweat glands or had penetrated beyond them. In our series, the diagnosis of pseudo-epitheliomatous hyperplasia led only to unfortunate delay. Nonetheless we believe that pseudo-epitheliomatous hyperplasia exists and that the following is an example of the condition.

The case was one of chronic osteomyelitis following a compound fracture of the tibia 23 years before. There was no clinical evidence of malignancy and amputation was carried out because of the offensive smell and general inconvenience caused by the sinus and cavity (Fig. 4) which had become extensively lined by squamous epithelium. Desquamated keratinized cells filled the cavity and were probably largely responsible for the bad smell. Despite occasional keratinized epithelial 'pearls' of the type illustrated in Fig. 5, the lesion was classified as benign. The patient has been in good health since the amputation and if he remains well it will never be known if the lesion was truly pseudo-epitheliomatous or whether a very early carcinoma was cured by the amputation.

There can be no doubt that true carcinoma sometimes develops insidiously in the depths of an epithelialized sinus or cavity. Figure 6 illustrates such a case. A cavity has become almost filled by a proliferating squamous carcinoma which may have been present for a long time before the sinus to the surface became sufficiently involved to indicate the need for biopsy (Fig. 7). Such insidious development is not invariable and a papillary tumour may appear in the skin at the margin of the sinus (Fig. 8), leaving the depths free from tumour.

The recognition of a sarcoma in biopsy material may also be difficult. In two of our three cases of sarcoma the histological diagnosis was straightforward but in the third the diagnosis remained 
unsettled and indefinite even when the amputated limb was available for examination. A woman had had chronic osteomyelitis of the left tibia, near its lower end, for 20 years. In November 1953 a mass of 'granulation tissue' appeared at the orifice of the sinus. A month later a pathological fracture occurred and made amputation essential. The appearance of the gross specimen (Fig. 9) suggested tumour but the histological appearances, perhaps because of changes due to the limb having been preserved in the deep freeze before fixation, were again interpreted as vascular granulation tissue (Fig. 10). After an interval of five months, however, the patient was readmitted to hospital having had pain in the chest for six weeks and a lump on her back. She died within a few days and, at necropsy, masses of tumour were present in the lungs and vertebrae. Microscopically (Figs. 11 and 12) these tumours still resembled the 'granulation tissue' of the primary tumour.

\section{DISCUSSION}

Although malignancy in scars, ulcers, and sinuses is now referred to as 'Marjolin's ulcer' (British Medical Dictionary, 1961), Marjolin did not regard the warty ulcers that he described in 1828 as malignant. It was Smith in 1850 who identified cancers in scars with the warty ulcers of Marjolin, and DaCosta in 1903 who used the name 'Marjolin's ulcer' for malignant transformation in previously simple chronic ulcers of the leg. We feel, as a result of our study, that Marjolin's ulcer, as now defined, includes tumours that are by no means identical in their behaviour, although histologically indistinguishable, and that the tumours that develop in sinuses and ulcers behave more aggressively than those that develop in scars.

The number of our cases of malignancy in scars is admittedly small but in each case the clinical course was relatively benign and in keeping with the behaviour to be expected in the light of the results of Treves and Pack (1930) and Lawrence (1952), who studied much larger numbers of cancers in burn scars. In our cases of malignancy in sinuses and chronic ulcers, however, the figures do not substantiate the view that the degree of malignancy is usually low. This has been borne out by a personal communication from Mr. W. L. Turner who found that the patients described by Marks and Turner (1950) all died of malignancy within a few months, although at the time the paper was written, the prognosis was thought to be good.

Scars of all types are very common, and even burn scars are not rare, but malignant change in scars is so unusual that we could find only three cases in the large amount of material indexed by the
Liverpool Cancer Control Organization. The low incidence was unexpected because there is a certain $\stackrel{-}{\Rightarrow}$ amount of experimental and other evidence that a $\stackrel{F}{\rho}$ scar or the trauma necessary to cause a scar can 0 contribute to the development of tumour (Pullinger, 흘 1943; Orr, 1958; Gowing, 1961). The rarity of $\frac{\bar{F}}{\frac{7}{2}}$ natural tumours in scars seems to support the $\stackrel{\mathbb{Q}}{\Omega}$ suggestion that trauma is no more than a cocarcinogenic factor and that ordinarily the additional factors necessary for tumour formation are not. present. Trauma itself may be a factor in the 'acute' $\overrightarrow{\vec{\omega}}$ wound cancers of Treves and Pack (1930) and in $\stackrel{\omega}{S}$ cases like those described by Gardner (1959) but no용 examples of this type of tumour were found in our $\vec{\theta}$ material. In our material the influence of scar $\sigma$ tissue is more likely to have contributed towards 07 carcinogenesis, as might be expected from the experi- $\omega$ mental results of Orr (1934 and 1935).

Although scars are common, chronic sinuses following osteomyelitis are now rare. The presence $z$ in our material of 11 cases of malignancy in sinuses almost certainly suggests that in sinuses a cocarcinogenic factor may be acting along with scar tissue. $\mathbb{\Phi}$ The growth-promoting factor that Menkin (1960) claims to have demonstrated in inflammatory exudates and which, he suggests, is capable of acting $\omega$ as a cocarcinogen may be such a factor. Varicose ulcers may occupy an intermediate position between simple scars and chronic sinuses, having, like sinuses, a combination of scar tissue and inflam- $\stackrel{2}{\not}$ matory exudate, although the inflammatory exudate $\stackrel{\unrhd}{\unrhd}$ may not be as abundant or as rich in growth- $\overrightarrow{\hat{O}}$ promoting factor as in the case of chronic sinuses. 3 In varicose ulcers there may also be the additional factor of erythema ab igne, so common among? women in Britain. This possible factor has been discussed by Peterkin (1955).

The photographs are the work of Mr. F. Beckwith, of the Department of Pathology, University of Liverpool.

\section{REFERENCES}

British Medical Dictionary (1961). British Medical Dictionary, edited Sir Arthur S. MacNalty. Caxton Publ. Co., London.

DaCosta, J. C. (1903). Ann. Surg., 37, 496.

Dodd, H., and Cockett, F. B. (1956). The Pathology and Surgery of the Veins of the Lower Limb, p. 389. Livingstone, Edinburgh N and London.

Gardner, A. Ward (1959). Lancet, 1, 760.

Gowing, N. F. C. (1961). J. forens. Med., 8, 116.

Hawkins, C. (1835). Med.-chir. Trans., 19, 19.

Lawrence, E. A. (1952). Surg. Gynec. Obstet., 95, 579.

Marjolin, J. N, (1828). Dictionnaire de médicine, vol. 21, p. 46. Paris.

Marks, K. L., and Turner, W. L. (1950). Brit. J. Surg., 38, 206.

Menkin, V. (1960). Brit. med. J., 1, 1585.

Orr, J. W. (1934). Brit. J. exp. Path., 15, 73. (1935). Ibid., 16, 121.

(1958). Brit. med. Bull., 14, 99.

Pullinger, B. D. (1943). J. Path. Bact., 55, 301.

Peterkin, G. A. Grant (1955). Brit. med. J., 2, 1599.

Smith, R. W. (1850). Dublin Q. J. med. Sci., 9, 257.

Treves, N., and Pack, G. T. (1930). Surg. Gynec. Obstet., 51, 749.

White, C., and Weidman, F. D. (1927). J. Amer. med. Ass., 88, 1959.

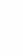

